\title{
To Study the Predictive Value of Umbilical Cord Blood Bilirubin Levels Term Neonates as Marker of Neonatal Hyperbilirubinemia
}

\author{
Jillela Mahesh Reddy ${ }^{1}$, Jonnala Umesh ${ }^{2}$ \\ ${ }^{1,2}$ Assistant Professor, Department of Paediatrics, Chalmeda Anandrao Institute of Medical Sciences, \\ Karimnagar, Telangana. \\ Corresponding Author: Jonnala Umesh
}

\begin{abstract}
Background: Infants who are clinically jaundiced in the first few days are more likely to develop hyperbilirubinemia. Hyperbilirubinemia is the most common medical problem in newborn infants. It is the most important cause for hospital readmissions during the early neonatal period and also the cause for neonatal morbidity.
\end{abstract}

Objective: In this prospective study we are going to evaluate the predictive value of cord bilirubin level for identifying term neonates for subsequent hyperbilirubinemia.

Materials and Methods: Cord bilirubin levels at birth and subsequently serum bilirubin levels at $72 \mathrm{~h}$ were assessed in 291 neonates. The cutoff value was estimated beyond which there was significant hyperbilirubinemia. Statistics employed include quantitative data which is expressed in terms of mean and SD and qualitative in terms of proportions and receiver operator characteristic curve used to find cut-off value and to find sensitivity and specificity.

Results: The cutoff value of cord bilirubin $>2$ $\mathrm{mg} / \mathrm{dl}$ had sensitivity and specificity of 77.97 and $56.90 \%$, respectively, with positive predictive value of 31.51 and negative predictive value of $91.03 \%$ for subsequent hyperbilirubinemia.

Conclusion: To decreases the significant burden of untreated severe neonatal jaundice, cord serum bilirubin can be used as a screening tool to identify the neonatal jaundice in term and this prediction of neonatal hyperbilirubinemia has widespread implication especially in our country where there are limited resources.
Keywords: Hyperbilirubinemia, Neonatal morbidity, cord serum bilirubin

\section{INTRODUCTION}

Hyperbilirubinemia also known as "jaundice" is yellowish green pigmentation of the sclera and skin caused by an increase in bilirubin production or a defect in bilirubin elimination. It is one of the most common problems in neonatal period estimated to occur in nearly $60 \%$ of the term infants in the first week of life. Under normal circumstances, the level of indirect reacting bilirubin in umbilical cord serum is $1-3 \mathrm{mg} / \mathrm{dl}$ and rises at a rate of less than $5 \mathrm{mg} / \mathrm{dl} / 24 \mathrm{hrs}$. Thus jaundice becomes visible on the $2^{\text {nd }}-3^{\text {rd }}$ day ( 36 to $72 \mathrm{hrs}$ ) usually peaking by the $3^{\text {rd }}$ day of life. Among preterm babies, age of onset of physiological jaundice is similar to term babies, it may manifest earlier but never before 24 hours of age. The maximum intensity of jaundice is reached on the 5 th or 6 th day and may persist upto 14 days ${ }^{[1]}$. Worldwide neonatal hyperbilirubinemia is one of the major issues in clinical practice. Most of the newborns have mild jaundice but all the newborns should be carefully monitored because of the potential toxicity of bilirubin. Severe untreated neonatal hyperbilirubinemia can lead to acute bilirubin encephalopathy (ABE) ${ }^{[2]}$. Every newborn develops an unconjugated serum bilirubin level $>1.8 \mathrm{mg} / \mathrm{dl}$ initial week of life after birth. The concentration of total serum 
bilirubin (TSB) is the standard method to evaluate hyperbilirubinemia in neonates. When the TSB concentration will be more than $5 \mathrm{mg} / \mathrm{dl}$, yellow coloration of skin could be visible which indicates jaundice. The potential risk of developing bilirubin encephalopathy or even kernicterus is high in babies with elevated serum bilirubin level. The sequelae could be serious as patients may develop cerebral palsy, sensorineural deafness and mental retardation ${ }^{[3]}$. When serum bilirubin in term newborn is $\geq 12 \mathrm{mg} / \mathrm{dl}$ at $24 \mathrm{hrs}$ of life, 15 $\mathrm{mg} / \mathrm{dl}$ at $48 \mathrm{hrs}$, and $17 \mathrm{mg} / \mathrm{dl}$ at $72 \mathrm{hrs}$ then it is said to be neonatal hyperbilirubinemia [4].

The American Academy of Pediatrics (AAP) recommends that newborns discharged within 48 hours should have a follow-up visit after 2-3 days to detect significant jaundice and other problems. In developing countries like India, this recommendation is not practical due to limited follow up facilities. Early treatment of jaundice with phototherapy is effective, simple and cheap as compared to the treatment of severe neonatal jaundice with exchange transfusion which is time consuming, costly, associated with complications and requires skilled personnel. Thus the early prediction of jaundice offers an attractive option for picking up babies at risk of Neonatal Hyperbilirubemia. Many investigators have tried to find a simple marker to predict hyperbilirubinemia and its subsequent course in newborns like cord bilirubin estimation, bilirubin estimation during 6 to 24 hours of age, predischarge hour specific bilirubin estimation and transcutaneous bilirubin measurement. Cord Bilirubin levels are easy to perform and may offer an attractive predictive marker for hyperbilirubinemia occurring later on ${ }^{[5]}$. Prompt treatment of hyperbilirubinemia is crucial, as well as assessment of the risk of development of hyperbilirubinemia. Thus, the investigation of parameters that might help in predicting the development of significant hyperbilirubinemia is justifiable and necessary.

Over the years many efforts have been made to identify the newborns likely to develop severe hyperbilirubinemia. Various strategies have been studied in order to reduce the duration of hospital stay for normal babies and identify those who may need prior treatment before developing significant hyperbilirubinemia. Follow up within 1-2 days of early discharge; umbilical cord bilirubin levels; routine predischarge serum bilirubin levels; transcutaneous bilirubin measurement and clinical assessment of risk factors of jaundice are various strategies to predict significant hyperbilirubinemia ${ }^{[5]}$. Others have studied the relevance of cord blood albumin levels, hydrogen peroxide levels, alfa fetoprotein levels \& alkaline phosphatase levels as predictors of significant neonatal hyperbilirubinemia.

In current scenario, it's desirable to identify term newborns, who are at risk of developing significant hyperbilirubinemia much before clinical diagnosis, in order to implement early treatment and minimize the risk of bilirubin dependent brain damage. There are very few studies done in India to find out predictive values of bilirubin in cord blood in term newborns as marker for hyperbilirubinemia.

However, the aim of the present study is to see the predictive cord blood bilirubin levels in term neonates as marker of neonatal hyperbilirubinemia.

\section{MATERIAL AND METHODS}

Present prospective study was conducted in the Department of Pediatrics, Chalmeda Anand Rao Institute of Medical Sciences, over a period of 12 months from January 2019 to December 2019. The study was approved by Institutional Ethics Committee. Written consent was obtained from the parents or legal guardians before recruitment. Only full-term (gestational age $>37$ weeks) neonates were recruited to the study. Neonates of both genders delivered consecutively by any type of delivery in the 
Department of Obstetrics and Gynecology were prospectively enrolled in the study. Neonates with aggravate hyperbilirubinemia, birth weight $<2000 \mathrm{~g}$. The samples of 219 patients were enrolled in the study.

\section{INCLUSION CRITERIA}

- All healthy newborns with gestational age $\geq 37$ weeks

- Both genders

- From any mode of delivery

- Apgar score of more than 7 at fifth minutes of life

\section{EXCLUSION CRITERIA}

- Newborns who later develop significant illness requiring NICU admission like Septicemia, meningitis ARDS etc

- Newborns with major congenital malformations.

- Conjugated hyperbilirubinemia

- Newborns with Gestational age < 37 weeks

\section{Statistical Analysis}

Result was analyzed using statistical software statistical package for the social sciences 25. Qualitative data were expressed in frequency and percentage, while quantitative data were expressed in mean \pm standard deviation. Receiver operating characteristic (ROC) curve were used to analyze the pattern of bilirubin levels.

\section{RESULTS}

Maximum newborns (91.10\%) had birth weight between $2.5-3.99 \mathrm{kgs}$. $8.20 \%$ of newborns had birth weight below $2.5 \mathrm{kgs}$ Only $0.70 \%$ newborns had birth weight $>4 \mathrm{kgs}$. Among 219 newborns enrolled in the study, $47.1 \%$ were female babies and $52.9 \%$ were male babies. B group was the most common blood group (86 newborns). Caesarean Delivery was observed in most of the patients shown in bellowed table no. 1

With ROC analysis, (Figure 1), the mean cord bilirubin level was $1.64 \pm 0.62$ $\mathrm{mg} / \mathrm{dl}$. The area under curve was 0.745 . The mean total bilirubin at $72 \mathrm{~h}$ was $10.57 \pm 3.38$ $\mathrm{mg} / \mathrm{dl}$. There were 48 newborns who had serum bilirubin $>14 \mathrm{mg} / \mathrm{dl}$ at $72 \mathrm{~h}$ (Table 2).

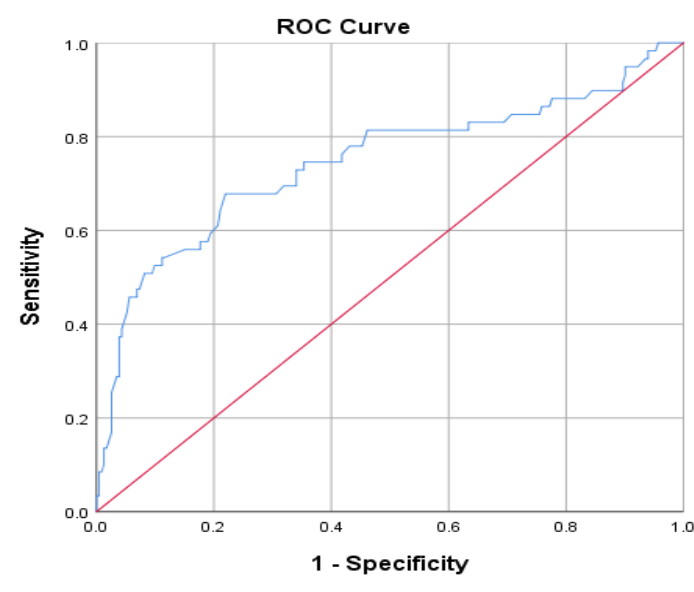

Diagonal segments are produced by ties.

Figure 1: Receiver operating characteristic curve showing association of cord bilirubin levels and requirement of phototherapy at $72 \mathrm{~h}$ of life

Table 1: The baseline characteristics of enrolled mothers and newborns.

\begin{tabular}{|c|c|}
\hline Variable & Frequency $(\%) /$ Mean \pm SD \\
\hline \multicolumn{2}{|r|}{ S } \\
\hline Male & $154(52.9)$ \\
\hline Female & $137(47.1)$ \\
\hline GA (Mother) & $38.15 \pm 0.948$ \\
\hline Birth Weight(Baby) & $2.95 \pm 0.39$ \\
\hline$\leq 2.499 \mathrm{Kg}$ & $24(8.20 \%)$ \\
\hline $2.5-3.99 \mathrm{Kg}$ & $265(91.10 \%)$ \\
\hline$\geq 4 \mathrm{Kg}$ & $2(0.70 \%)$ \\
\hline Cord Bilurubin & $1.64 \pm 0.62$ \\
\hline Total Sr. Bilirubin & $10.57 \pm 3.38$ \\
\hline \multicolumn{2}{|l|}{ Mode of Delivery } \\
\hline Vaginal Delivery & $72(24.80 \%)$ \\
\hline Ceaserean Delivery & $218(75.20 \%)$ \\
\hline \multicolumn{2}{|l|}{ Cord Bilurubin } \\
\hline$<2$ & $145(49.8)$ \\
\hline$\geq 2$ & $146(50.2)$ \\
\hline \multicolumn{2}{|c|}{ Blood Group (Mother) } \\
\hline $\mathrm{A}$ & $77(26.5)$ \\
\hline $\mathrm{B}$ & $84(28.9)$ \\
\hline $\mathrm{AB}$ & $49(16.8)$ \\
\hline $\mathrm{O}$ & $81(27.8)$ \\
\hline \multicolumn{2}{|l|}{ Blood Group (Baby) } \\
\hline A & $84(28.9)$ \\
\hline $\mathrm{B}$ & $86(29.6)$ \\
\hline $\mathrm{AB}$ & $44(15.1)$ \\
\hline $\mathrm{O}$ & $77(26.5)$ \\
\hline
\end{tabular}

Table 2 : Relationship between cord bilirubin and serum bilirubin at $72 \mathrm{~h}$

\begin{tabular}{|l|l|l|l|}
\hline \multirow{2}{*}{ Serum Bilirubin } & \multicolumn{2}{|l|}{ Cord Bilirubin Level } & \multirow{2}{*}{ Total } \\
\cline { 2 - 3 } & $\mathbf{<}$ & $\mathbf{2}$ & \\
\hline$<14$ & $137(47.1)$ & $106(36.4)$ & $243(83.5)$ \\
\hline$>14$ & $8(2.7)$ & $40(13.7)$ & $48(16.5)$ \\
\hline Total & $145(49.8)$ & $146(50.2)$ & $291(100)$ \\
\hline
\end{tabular}

The cord bilirubin of $>2$ had sensitivity and specificity of $77.97 \%$ and $56.90 \%$, respectively, with positive predictive value of $31.91 \%$ and negative predictive value of 91.03 . The strength of 
association of cord bilirubin $>2.02 \mathrm{mg} / \mathrm{dl}$ and requirement of phototherapy at $72 \mathrm{~h}$ was found to be significant $(\mathrm{p}<0.001)$.

\section{DISCUSSION}

The

present

prospective observational study undergone among 291 term babies born in a tertiary care hospital. The objective was to identify whether umbilical cord serum bilirubin values soon after birth could predict the risk of significant neonatal hyperbilirubinemia in early neonatal period.

High cord bilirubin levels among neonates who later become severely icteric is compared to cord bilirubin levels in nonjaundiced neonates. The above was based in the fact that the mechanisms of development of jaundice in early post-natal period had already occurred in late fetal life. Mostly all fetal bilirubin is unconjugated, due to a decreased ability of the fetal liver to conjugate bilirubin.

Cord blood estimation was chosen because it is a non-invasive method and the results are available within few hours after birth. Thus, the babies at risk for developing hyperbilirubinemia can be detected at birth in a non-invasive way if the neonate leaves the hospital within the first few postnatal days. In addition, the use of cord blood bilirubin values may help predict infants with low risk for hyperbilirubinemia and minimize an unnecessary prolongation of hospitalization ${ }^{[6-8]}$. In a study by Taksande et al., prevalence was $9.5 \%$ only because the cutoff for significant hyperbilirubinemia on 3rd day of life was taken as $17 \mathrm{mg} \%{ }^{[9]}$.

In present study, newborns who developed significant hyperbilirubinemia male:female ratio was $1.18: 1 \quad 54.23 \%$ (32/59) newborns who developed significant hyperbilirubinemia were male babies and $45.76 \%$ were female babies.

Male gender is a known risk factor for hyperbilirubinemia. In a study done by Naranget al, incidence of hyperbilirubinemia in males was $64.2 \%$. In similar study done by Alpay et al, $37(61.6 \%)$ newborns who developed significant hyperbilirubinemia were male babies. ${ }^{[10-12]}$

In the present study, ROC curve analysis with cord bilirubin levels $>2 \mathrm{mg} / \mathrm{dl}$ had area under the curve of $74.5 \%$. Sensitivity was found to be $77.97 \%$ while specificity was found to be $56.90 \%$. The above indicated that at the bilirubin value of $>2 \mathrm{mg} / \mathrm{dl}$, the test would predict more true positives than true negatives. Several studies also reported the importance of cord bilirubin levels at birth in prediction of hyperbilirubinemia. Taksande et al found that the cord serum bilirubin values $>2$ $\mathrm{mg} / \mathrm{dl}$ has a sensitivity $89.5 \%$, specificity $85 \%$, negative predictive value of $98.7 \%$ and positive predictive value of $38.8 \%$ which is similar to that of the present study. ${ }^{[9]}$

Ahire et al. predicted the serum bilirubin $>3 \mathrm{mg} / \mathrm{dl}$ on the first day of life had $100 \%$ sensitivity of predicting subsequent jaundice at $48 \mathrm{~h}$ of life with bilirubin levels $>10.58 \mathrm{mg} / \mathrm{dl}{ }^{[13]}$. Knupfer et al. observed that serum bilirubin $>1.74 \mathrm{mg} /$ $\mathrm{dl}$ on the first day of life had $97 \%$ sensitivity of predicting a subsequent serum bilirubin levels $>16 \mathrm{mg} / \mathrm{dl}$ at $72 \mathrm{~h}$ of life. ${ }^{[14]}$

In our study, the cord bilirubin level $>2 \mathrm{mg} / \mathrm{dl}$ had the highest sensitivity $(77.97 \%)$, and this critical bilirubin levels had a very high negative findings, a critical cutoff level of cord bilirubin was $2 \mathrm{mg} / \mathrm{dl}$ predicted $78 \%$ of newborn who developed jaundice. However, the cord bilirubin <2 $\mathrm{mg} / \mathrm{dl}$ did not completely exclude the development of significant hyperbilirubinemia. Only $2.7 \%$ of newborn with cord bilirubin levels of $<2 \mathrm{mg} / \mathrm{dl}$ developed jaundice. A $91.03 \%$ of negative predictive value suggests that the measurement of cord serum bilirubin can help in identifying those newborn who are unlikely to require further evaluation and intervention.

The strength of present study, bilirubin cut off value was determined using receiver operating characteristic analysis and the test is highly significant $(\mathrm{P}$ value $<0.0001)$. The data was not evaluated on 
nomograms. This would better reflect the geographic, cultural and various demographic characters distinctive to present population. Study also has some limitations like other studies. Some of the neonates did not turn up in outpatient department for follow-up and the access to sample collection at $72 \mathrm{~h}$ of life was denied by some of the parents which made it difficult to consider them as cases. The sample size was small which causes difficulty in creating significant relationships between the two values of bilirubin levels.

\section{CONCLUSION}

Cord blood bilirubin values can be used as a predictor of neonatal jaundice. The present study shows Cord bilirubin level $>2$ $\mathrm{mg} / \mathrm{dl}$ had more sensitivity and specificity can be taken as a cutoff value above which, a neonate would develop hyperbilirubinemia.

\section{Acknowledgement: None}

\section{Conflict of Interest: None}

\section{Source of Funding: None}

\section{Ethical Approval: Approved}

\section{REFERENCES}

1. Ram N, Bagalkot $P$ early predictor of significant hyperbilirubinemia in preterm neonates using 24 hours serum bilirubin Indian journal of applied research. 2018 May 19;8(3).

2. Radmacher PG, Groves FD, Owa JA, Ofovwe GE, Amuabunos EA, Olusanya BO, Slusher TM. A modified Bilirubininduced neurologic dysfunction (BINDM) algorithm is useful in evaluating severity of jaundice in a resourcelimited setting. BMC pediatrics. 2015 Apr 1;15(1):1

3. Ramamoorthy K, Abilash MS. Cord blood bilirubin used as an early predictor of hyperbilirubinemia.
International Journal of Contemporary Pediatrics. 2018 Jun 18.

4. Ambalavanan N, Carlo WA. Jaundice and Hyperbilirubinemia in the NewbornKliegman RM, Behrman RE, Jenson HB, Stanton BM. Nelson textbook of pediatrics. $20^{\text {th }}$ edition. Philadelphia, PA. Elsevier Health Sciences; 2015. p. 871-875.

5. Ahire N, Sonawane R, Gaikwad R, Patil $\mathrm{S}$, Sonawane T. Study of Correlation of Cord Blood Bilirubin with Neonatal Hyperbilirubinemia. MVP Journal of Medical Sciences. 2016 Feb 29;3(1):606.

6. Watchko JF. Neonatal Indirect hyperbilirubinemia and kernicterus. In: Gleason CA, Devaskar SU, editors. Avery's Diseases of the Newborn. 9th ed. Philadelphia (USA): Elsevier; 2012. p. 1123-42.

7. Suchonska B, Wielgos M, Bobrowska $\mathrm{K}$, Marianowski L. Concentration of bilirubin in the umbilical blood as an indicator of hyperbilirubinemia in newborns. Ginekol Pol. 2004;75(10):749-53.

8. Knudsen A. Prediction and non-invasive assessment of neonatal jaundice in the term healthy newborn infant. Acta Paediatr. 1996;85(4):393-7.

9. Taksande A, Vilhekar K, Jain M, Zade P, Atkari S, Verkey S. Prediction of the development of neonatal hyperbilirubinemia by increased umbilical cord blood bilirubin. Curr Pediatr Res. 2005:9(1-2):59.

10. Alpay F, Sarici SÜ, Tosuncuk HD, Serdar MA, Inanç N, Gökçay E. The value of first-day bilirubin measurement in predicting the development of significant hyperbilirubinemia in healthy term newborns. Pediatrics. 2000 Aug 1;106(2):e16.

11. Watchko JF, Oski FA. Bilirubin 20 $\mathrm{mg} / \mathrm{dL}=$ vigintiphobia. Pediatr. 1983 Apr 1;71(4):660-3

12. Narang A, Gathwala G, Kumar P. Neonatal Jaundice: An analysis of 551 
cases. Indian Pediatr. 1997 May;34:42932.

13. Ahire N, Sonawane R, Gaikwad R, Patil S, Sonawane T. Study of correlation of cord blood bilirubin with neonatal hyper bilirubinaemia. MVP J Med Sci. 2016; 3(1):60-6.

14. Knüpfer M, Pulzer F, Gebauer C, RobelTillig E, Vogtmann C. Predictive value of umbilical cord blood bilirubin for postnatal hyperbilirubinaemia. Acta Paediatr. 2005;94(5):581-7.

How to cite this article: Reddy JM, Umesh J. To study the predictive value of umbilical cord blood bilirubin levels term neonates as marker of neonatal hyperbilirubinemia. International Journal of Research and Review. 2021; 8(6): 18-23. DOI: https://doi. org/10.52403/ijrr.20210603

$* * * * * *$ 